\title{
Direct detection of resistance to fluoroquinolones/SLIDs in sputum specimen by GenoType MTBDRs/ v.2.0 assay A study from Eastern Uttar Pradesh, India
}

Kamal Singh ${ }^{1}$, Richa Kumari ${ }^{1}$, Smita Gupta ${ }^{1}$, Rajneesh Tripathi ${ }^{1}$, Anjali Srivastava ${ }^{1}$, Vidisha Shakya ${ }^{2}$, Ankush Gupta ${ }^{3}$ and Shampa Anupurba ${ }^{1 *}$ (1)

\begin{abstract}
Background: According to World Health Organization (WHO), drug-resistant tuberculosis (DR-TB) is a major contributor to antimicrobial resistance globally and continues to be a public health threat. Annually, about half a million people fall ill with DR-TB globally. The gradual increase in resistance to fluoroquinolones (FQs) and second-line injectable drugs (SLIDs), poses a serious threat to effective TB control and adequate patient management. Therefore, WHO suggests the use of GenoType MTBDRs/ v.2.0 assay for detection of multiple mutations associated with FQs and SLIDs. Hence, the study was conducted to determine the prevalence of resistance to FQs and SLIDs by comparing direct GenoType MTBDRs/ v.2.0 assay with phenotypic drug susceptibility testing (DST).
\end{abstract}

Methods: The study was conducted on 1320 smear positive sputum samples from a total of 2536 RR-TB, confirmed by GeneXpert MTB/RIF. The smear positive specimens were decontaminated, and DNA extraction was performed. Furthermore, the extracted DNA was used for GenoType MTBDRs/ v.2.0 assay. While 20\% of the decontaminated specimens were inoculated in Mycobacterium growth indicator tube (MGIT) for drug susceptibility testing (DST).

Results: Out of 1320 smear positive sputum samples, 1178 were identified as Mycobacterium tuberculosis complex (MTBC) and remaining were negative by GenoType MTBDRs/ v.2.0 assay. Of the 1178 MTBC positive, 26.6\% were sensitive to both FQs and SLIDs, whereas $57.3 \%$ were only FQs resistant and $15.9 \%$ were resistant to both FQs and SLIDs. Further DST of 225 isolates by liquid culture showed that $17 \%$ were sensitive to both FQs and SLIDs, $61.3 \%$ were only FQs resistant and $21.3 \%$ were resistant to both. The specificity for FQs and SLIDs was $92.31 \%$ and $100 \%$ whereas sensitivity was $100 \%$ respectively by GenoType MTBDRs/ v.2.0 assay in direct sputum samples.

Conclusions: Our study clearly suggests that GenoType MTBDRs/ v.2.0 assay is a reliable test for the rapid detection of resistance to second-line drugs after confirmation by GeneXpert MTB/RIF assay for RR-TB. Though, high rate FQ (ofloxacin) resistance was seen in our setting, moxifloxacin could be used as treatment option owing to very low resistance.

Keywords: GenoType MTBDRs/ v.2.0 assay, Fluoroquinolones (FQs), Second-line injectable drugs (SLIDs), RR-TB, MDR-TB, XDR-TB

*Correspondence: shampa_anupurba@yahoo.co.in

1 Department of Microbiology, Institute of Medical Sciences, Banaras Hindu University, Varanasi, Uttar Pradesh, India

Full list of author information is available at the end of the article

(c) The Author(s) 2021. Open Access This article is licensed under a Creative Commons Attribution 4.0 International License, which permits use, sharing, adaptation, distribution and reproduction in any medium or format, as long as you give appropriate credit to the original author(s) and the source, provide a link to the Creative Commons licence, and indicate if changes were made. The images or other third party material in this article are included in the article's Creative Commons licence, unless indicated otherwise in a credit line to the material. If material is not included in the article's Creative Commons licence and your intended use is not permitted by statutory regulation or exceeds the permitted use, you will need to obtain permission directly from the copyright holder. To view a copy of this licence, visit http://creativecommons.org/licenses/by/4.0/. The Creative Commons Public Domain Dedication waiver (http://creativecommons.org/publicdomain/zero/1.0/) applies to the data made available in this article, unless otherwise stated in a credit line to the data. 


\section{Background}

Drug-resistant tuberculosis (DR-TB) has emerged as an enormous global challenge for TB control. It develops either because of an infection with a resistant strain or as a result of inadequate treatment. Multidrug-resistant TB (MDR-TB) is the form of TB that is resistant to rifampicin and isoniazid, the two most powerful anti-TB drugs [1]. It is of grave concern to public health, with higher mortality rates than drug-susceptible TB [2]. These TB patients require treatment with second-line drugs that are costlier and have increased toxicity; and remain infectious longer than patients infected with drug-susceptible strains [3]. Extensively drug-resistant TB (XDR-TB) is defined as MDR-TB plus resistance to fluoroquinolones (FQs) and one of the second line injectable drugs (SLIDs) utilized in MDR-TB treatment regimens [4].

With the increasing use of the GeneXpert MTB/RIF assay for simultaneous detection of TB and resistance to rifampicin (without further testing for isoniazid resistance), an increasing number of RR-TB cases are being detected and notified [5]. Rifampicin resistant TB (RRTB) is considered as a surrogate marker for MDR-TB [6].

According to the WHO report 2019, there were an estimated 484 000 (range, 417 000-556 000) incident cases of MDR/RR-TB in 2018. Worldwide fifty percent cases of MDR/RR-TB were in India (27\%), China (14\%), and Russia (9\%). In 2018, there were about 214000 (range, 133 000-295 000) deaths from MDR/RR-TB. Among the MDR/RR-TB patients, $59 \%$ were notified as XDR-TB. The five countries that reported the foremost number of XDR-TB cases were Belarus, India, Russia, South Africa, and Ukraine [7].

In recent years several molecular methods have been developed for the diagnosis of tuberculosis and detection of drug resistance, including line probe assays [8]. Most of the species of Mycobacteria grow slowly with a generation time of 18 to $24 \mathrm{~h}$; resulting in delay of TB diagnosis by conventional methods [9]. Molecular techniques reducing turnaround time (TAT) are able to detect and identify Mycobacterium tuberculosis complex (MTBC) within 1-2 days instead of several weeks with the traditional methods [10]. It is essential to detect drug resistance to second-line drugs before initiating treatment for better management of MDR-TB.

Line probe assays (LPAs) detect mutations associated with drug resistance. The Genotype MTBDRplus assay (Hain Lifescience Nehren Germany) identifies MTBC and detects resistance to rifampicin and isoniazid. GenoType MTBDRsl v.1.0 assay detects resistance to FQs, SLIDs and ethambutol (EMB) [11]. However, in recent years several novel mutations were identified that also confer resistance. Thus, WHO recommended the use of GenoType MTBDRsl v.2.0 assay (Hain Lifescience Nehren
German) which detects multiple mutations which are associated with resistance to FQs and SLIDs. Mutations in $g y r A$ and $g y r B$ are detected for resistance to FQs, while resistance to SLIDs are detected through mutations in rrs and eis gene [12]. In 2018, Revised National Tuberculosis Control Program (RNTCP) recommended GenoType MTBDRsl v.2.0 as the initial test, instead of phenotypic drug susceptibility testing (DST) [13]. Uttar Pradesh is a region where highest number of $\mathrm{TB}$ cases are reported annually in India (https://tbfacts.org/tb-statistics-india/). With this in mind, the study was designed to compare the direct GenoType MTBDRsl v.2.0 assay with phenotypic drug susceptibility testing and determine the prevalence of resistance to FQs and SLIDs.

\section{Methods}

\section{Location and samples}

The study was undertaken in TB Culture \& DST lab, Department of Microbiology, Institute of Medical Sciences, Banaras Hindu University, Varanasi, India, over the period of January 2019 to December 2019. Specimen processing, inoculation, and DST were performed in RNTCP certified laboratory with well-equipped BSL II \& III facilities under standard biosafety precautions. All presumptive TB samples were directly detected by GeneXpert MTB/RIF assay, which identified TB along with rifampicin resistance (RR). Since $R R$ is a surrogate marker for MDR-TB, the diagnosis of MDR-TB was based on this data. Over a period of one year, a total of 2536 RR-TB sputum specimens were collected, among which 1320 samples were smear positive and 1216 were smear negative. The smear positive samples were included in this study and subjected to GenoType MTBDRsl v.2.0 assay while phenotypic DST was performed for $20 \%$ of the samples. Every fifth sample was systematically selected for culture.

\section{Specimen processing and Genomic DNA extraction}

The collected specimens were decontaminated as described elsewhere $[6,14]$. Briefly, specimens were decontaminated using $\mathrm{N}$-acetyl-L-cysteine and sodium hydroxide (NALC-NaOH) method. The decontaminated and concentrated sediments were used for Ziehl-Neelsen staining (ZN staining) as well as for DNA extraction and inoculation into BACTEC MGIT 960 (BD, USA) automated liquid culture system for DST.

DNA extraction was performed by using GenoLyse kit (Hain Lifescience, Nehren, Germany) according to manufacturer's instructions. In brief, $1000 \mu$ l of the decontaminated sample was centrifuged at $10,000 \times g$ for $15 \mathrm{~min}$. Supernatant was discarded and the pellet was re-suspended into $100 \mu \mathrm{l}$ lysis buffer followed by vortexing for $30 \mathrm{~s}$. This suspension was incubated in water bath at 95 
$\circ \mathrm{C}$ for $5 \mathrm{~min}$. Following this $100 \mu \mathrm{l}$ neutralization buffer was added and vortexed for $30 \mathrm{~s}$, then it was centrifuged at $13,000 \times g$ for $5 \mathrm{~min}$. The supernatant containing DNA was transferred in a separate tube for further use.

\section{GenoType MTBDRs/ v.2.0 assay}

The extracted genomic DNA was subjected to GenoType MTBDRsl v.2.0 assay for the detection of MTBC and resistance to FQs and SLIDs, according to the manufacturer's instructions (Hain Lifescience, Nehren, Germany).

\section{Drug susceptibility testing}

For 264 samples a portion of the decontaminated samples $(0.5 \mathrm{ml})$ was inoculated into a mycobacterium growth indicator tube (MGIT) and incubated in an automated BACTEC MGIT-960 system for a maximum of 42 days, with constant monitoring. ZN microscopy was performed from each positive-flagged MGIT tube to check for the presence of acid-fast bacilli (AFB). Simultaneously, a loopful of liquid culture was inoculated in the brain heart infusion (BHI) agar and incubated for $24 \mathrm{~h}$ to check the sterility of the positive culture tube [15]. To confirm MTBC, immunochromatography-based MPT64 rapid antigen detection kit (SD BIOLINE TB Ag, South Korea) was used [16]. The confirmed MTBC isolates were further subjected to DST using MGIT 960 system for ofloxacin $(2 \mathrm{ug} / \mathrm{ml})$, kanamycin $(2.5 \mathrm{ug} / \mathrm{ml})$, capreomycin $(2.5 \mathrm{ug} / \mathrm{ml})$ and moxifloxacin $(0.25 \mathrm{ug} / \mathrm{ml})$. The $H 37 R v$ strain was used as a quality control testing in DST.

\section{Statistical analysis}

The sensitivity and specificity of GenoType MTBDRsl v.2.0 assay was analyzed with MedCalc statistical software taking the phenotypic DST as gold standard.

\section{Results}

\section{GenoType MTBDRs/ v.2.0 assay}

Out of 1320 smear positive sputum samples, 1178 were identified as MTBC positive and 142 were negative by GenoType MTBDRsl v.2.0 assay. Of the 1178 valid results, $314(26.6 \%)$ were sensitive to both FQs and SLIDs, 676 (57.3\%) were only FQs resistant, and 188 (15.9\%) were resistant to both FQs and SLIDs. Resistant mutations found in gyrA gene were the most prevalent (930), followed by rrs gene (172), eis gene (30) and gyrB gene (25). The distribution, as well as band pattern of mutations, is summarized in Additional file 1: Tables S1-S3.

\section{Drug susceptibility testing}

Of the 264 samples inoculated for culture, 225 isolates were found $\mathrm{MTBC}$ positive in liquid culture, confirmed by immunochromatography-based MPT64 rapid antigen detection kit (SD BIOLINE TB Ag) with no growth on BHI agar plate, whereas 39 were found contaminated. Drug susceptibility testing of the 225 isolates by liquid culture showed that 39 (17.4\%) were sensitive to both FQ (ofloxacin) and SLID (kanamycin), 138 (61.3\%) were only FQ resistant and 48 (21.3\%) were both resistant to FQs and SLIDs. The sensitivity and specificity of GenoType MTBDRsl v.2.0 assay in detecting resistance to FQs and SLIDs is described in Table 1.

\section{Concordance between GenoType MTBDRs/ v.2.0 assay and Phenotypic DST}

For assessing the performance of GenoType MTBDRsl v.2.0 assay, phenotypic DST was taken as gold standard. GenoType MTBDRsl v.2.0 assay accurately identified all strains except one, as shown in Table 2, thus the overall concordance between GenoType MTBDRsl v.2.0 assay and phenotypic DST was 224/225.

\section{Drug resistance pattern}

The prevalence of overall resistance pattern to at least one drug was highest in ofloxacin 186/225, (82.6\%), followed by kanamycin 48/225, (21.3\%), capreomycin 46/225, (20.4\%), and moxifloxacin $2 / 225,(0.88 \%)$ (Table 3).

\section{Discussion}

The present study highlights the rapid and accurate diagnosis of drug resistant-TB directly from sputum specimens by using GenoType MTBDRsl v.2.0 assay, whereas, previous studies have shown that it could be performed on DNA extracted from culture isolates [17-20]. According to WHO, an effective treatment regimen depends on optimal susceptibility testing of $M$. tuberculosis to anti-TB drugs [21].

Under TB control programs DR-TB portends a prominent threat globally. Efficient treatment of MDR-TB and XDR-TB is very expensive, which is especially an issue in low-income countries. Therefore, a sensitive and specific diagnostic tool is essential for effective diagnosis and subsequent treatment.

In our study, the specificity for FQs and SLIDs was $92.31 \%$ and $100 \%$ whereas sensitivity was $100 \%$ respectively by GenoType MTBDRsl v.2.0 assay in direct sputum samples when compared against phenotypic DST. A previous study by Tagliani et al. [21] demonstrated a sensitivity and specificity of GenoType MTBDRsl v.2.0 assay for FQs was respectively $93 \%$ and $98.3 \%$ and for SLIDs $88.9 \%$ and $91.7 \%$, from culture positive isolates when compared with phenotypic DST.

A study from South Africa also showed that the GenoType MTBDRsl v.2.0 has shown an improvement in 
Table 1 Performance of GenoType MTBDRs/ v.2.0 assays compared Phenotypic DST in detecting resistance to FQs, SLIDs, and XDR-TB

\begin{tabular}{|c|c|c|c|c|}
\hline \multirow[t]{2}{*}{$\begin{array}{l}\text { GenoType MTBDRs/ v.2.0 } \\
\text { Assay }\end{array}$} & \multirow[b]{2}{*}{ Resistant } & \multirow[b]{2}{*}{ Susceptible } & \multicolumn{2}{|l|}{$\begin{array}{l}\text { FQs } \\
\text { Phenotypic DST }\end{array}$} \\
\hline & & & Total & Sensitivity $=100 \%$ \\
\hline Resistant & 186 & 1 & 187 & Specificity $=92.3 \%$ \\
\hline Susceptible & 0 & 38 & 38 & $N P V=100 \%$ \\
\hline \multirow[t]{3}{*}{ Total } & 186 & 39 & 225 & $P P V=98.41 \%$ \\
\hline & & & SLIDs & \\
\hline & Resistant & Susceptible & Total & Sensitivity $=100 \%$ \\
\hline Resistant & 48 & 0 & 48 & Specificity $=100 \%$ \\
\hline Susceptible & 0 & 177 & 177 & $N P V=100 \%$ \\
\hline \multirow[t]{2}{*}{ Total } & 48 & 177 & 225 & $P P V=100 \%$ \\
\hline & & & XDR-TB & \\
\hline \multirow{2}{*}{$\begin{array}{l}\text { GenoType MTBDRs/ v.2.0 } \\
\text { Assay }\end{array}$} & & & Phenotypic DST & \\
\hline & Resistant & Susceptible & Total & Sensitivity $=100 \%$ \\
\hline Resistant & 48 & 0 & 48 & Specificity $=100 \%$ \\
\hline Susceptible & 0 & 177 & 177 & $N P V=100 \%$ \\
\hline Total & 48 & 177 & 225 & $P P V=100 \%$ \\
\hline
\end{tabular}

$\mathrm{NPV}=$ negative predictive value; $\mathrm{PPV}=$ positive predictive value, $\mathrm{Cl}=95 \%$

Table 2 Concordance between GenoType MTBDRs/ v.2.0 Assay and phenotypic DST

\begin{tabular}{|c|c|c|c|c|}
\hline \multirow[t]{2}{*}{ Drugs } & \multicolumn{2}{|c|}{ Concordant results } & \multicolumn{2}{|c|}{ Discordant results } \\
\hline & $\begin{array}{l}\text { Resistant } \\
\text { by both } \\
\text { methods }\end{array}$ & $\begin{array}{l}\text { Sensitive } \\
\text { by both } \\
\text { methods }\end{array}$ & $\begin{array}{l}\text { Sensitive by } \\
\text { phenotypic } \\
\text { DST but } \\
\text { resistant by } \\
\text { GenoType } \\
\text { MTBDRs/ v.2.0 } \\
\text { Assay }\end{array}$ & $\begin{array}{l}\text { Resistant by } \\
\text { phenotypic } \\
\text { DST but } \\
\text { sensitive by } \\
\text { GenoType } \\
\text { MTBDRs/ v.2.0 } \\
\text { Assay }\end{array}$ \\
\hline FQs & 186 & 38 & 1 & 0 \\
\hline SLIDs & 48 & 177 & 0 & 0 \\
\hline XDR-TB & 48 & 177 & 0 & 0 \\
\hline
\end{tabular}

Table 3 Resistance pattern to second-line anti-tuberculosis drugs among the 225 MTB isolates

\begin{tabular}{lcl}
\hline Drugs & $\begin{array}{l}\text { Total No. of drug } \\
\text { resistant strains (\%) } \\
\mathbf{N}=\mathbf{2 2 5}\end{array}$ & $\begin{array}{l}\text { Total No. of drug } \\
\text { susceptible strains } \\
\text { (\%) }\end{array}$ \\
\hline Ofloxacin $(2 \mathrm{ug} / \mathrm{ml})$ & $186(82.66)$ & $39(17.33)$ \\
Kanamycin $(2.5 \mathrm{ug} / \mathrm{ml})$ & $48(21.33)$ & $177(78.66)$ \\
Capreomycin $(2.5 \mathrm{ug} / \mathrm{ml})$ & $46(20.4)$ & $179(79.5)$ \\
Moxifloxacin $(0.25 \mathrm{ug} / \mathrm{ml})$ & $2(0.88)$ & $223(99)$ \\
\hline
\end{tabular}

sensitivity and specificity for the determination of molecular resistance to both FQs (100\% and 98.9\%) and SLIDs (89.2\% and $98.5 \%)$ compared with the pooled sensitivity and specificity of GenoType MTBDRsl v.1.0 as reported by the WHO Expert Group [12].

A study from Lithuania where the sensitivity and specificity of the GenoType MTBDRsl v.2.0 to detect ofloxacin resistance mutations in the gyrA and $\operatorname{gyr} B$ genes compared to DST was $91 \%$ and $100 \%$. Whereas sensitivity and specificity to detect resistance mutations in the rrs and eis gene for aminoglycoside/cyclic peptides was $89 \%$ and $77 \%$ [22]. Brossier et al. [23] found the sensitivity and specificity of Genotype MTBDRsl v.2.0 assay was: FQs (94.8\% and 98\%), kanamycin (90.5\% and 94.3\%), amikacin $(91.3 \%$ and $100 \%)$, capreomycin (83\% and $100 \%)$, pre-XDR (83.3\% and $88.6 \%)$ and XDR (83\% and $100 \%)$, when compared with phenotypic DST. According to Yadav et al. [24], the sensitivity and specificity of Genotype MTBDRsl v.2.0 compared with phenotypic DST for detecting levofloxacin resistance was respectively $97.2 \%$ and $99.1 \%$, and for kanamycin resistance was respectively 92.5\% and $99.5 \%$.

Further, in our study FQ resistance were mainly due to mutations in $g y r A$, indicated by both distribution as well as band patterns. The major mutation was reported in MUT3C (D94G, 20.12\%), MUT1 (A90V, 2.54\%), MUT3B (D94N/Y, 1.10\%), MUT3A (D94A, 0.67\%), MUT2 (S91P, $0.50 \%$ ) and MUT3D (D94H, 0.25\%). For SLID the band pattern of mutations in rrs gene was MUT1 (A1401G, $7.31 \%)$ and eis gene MUT1 (C-14T, 0.42\%). In concordance with our result, Tagliani et al. [21] also reported the predominant mutations detected by Genotype MTBDRsl 
v2.0 as conferring FQs resistance in gyrA MUT1 (A90V, 35.6\%) and MUT3C (D94G, 20.5\%) mutations. According to data from Gardee et al. [12] the predominant mutation bands detected by MTBDRsl v2.0 conferring FQs resistance were in gyrA MUT3C (D94G, 44.2\%), MUT3A (D94A, 13.5\%), MUT3D (D64H, 11.5\%) and MUT3B (D94N/Y, 9.6\%), and the most frequently observed mutation for SLIDs resistance was rrs MUT1 (C1402T, 85.7\%).

The present study also showed the drug-resistant profiles among 225 MTBC isolates by phenotypic DST, which were: 186 (82.6\%), 48 (21.3\%), 46 (20.4\%) and 2 $(0.88 \%)$ to ofloxacin, kanamycin, capreomycin and moxifloxacin, respectively. In a study from China, the phenotypic DST showed that among $170 \mathrm{M}$. tuberculosis isolates, 94 (55.3\%), 25 (14.7\%), 13 (7.6\%) and 20 (11.8\%) were resistant to ofloxacin, kanamycin, amikacin and capreomycin, respectively [25]. According to Yadav et al. [24], levofloxacin and kanamycin resistance using phenotypic DST was respectively, 176/415 (42.4\%) and 40/415 (9.6\%). A study from India showed phenotypic resistance to ofloxacin (59.1\%), SLIDs (11.8\%,) and to both antibiotics $(10.0 \%)$ by phenotypic drug susceptibility testing using the MGIT 960 system [26]. According to Singh et al. [27], who used phenotypic drug susceptibility testing (DST) assess baseline resistance to second-line drugs DST, RR-TB positive patients also showed a high resistance to fluoroquinolones (FQs; levofloxacin 56\%; moxifloxacin $44 \%)$ followed by kanamycin (8\%) and capreomycin (6\%). None of the patients were resistant to the other drugs tested (amikacin, clofazimine and linezolid).

\section{Conclusions}

From this study we can clearly suggest that the sputum specimen with the clinical diagnosis of MTB could be directly subjected to GenoType MTBDRsl v.2.0 assay, after confirmation by GeneXpert MTB/RIF for rifampicin resistance (RR) and $\mathrm{ZN}$ staining. This bypasses the long incubation period required for liquid culture and DST and may help for the rapid detection of second line drug resistance for FQs and SLIDs in order to initiate treatment among the critical patients. The findings showed alarming level of FQ (ofloxacin) resistance from the geographical region (Uttar Pradesh) of India which contributes the highest cases of TB. However, another drug moxifloxacin could be used as treatment option owing to very low resistance.

\footnotetext{
Abbreviations

WHO: World Health Organization; DR-TB: Drug-resistant tuberculosis; FQs: Fluoroquinolones; SLIDs: Second-line injectable drugs; TB: Tuberculosis; MDR/ RR-TB: Multi drug resistance/rifampicin resistance TB; MGIT: Mycobacterium growth indicator tube; MDR-TB: Multidrug-resistant TB; XDR-TB: Extensively drug-resistant TB; TAT: Turnaround time; LPAs: Line probe assays; MTBC:
}

Mycobacterium tuberculosis complex; EMB: Ethambutol; DST: Drug susceptibility testing; RNTCP: Revised National Tuberculosis Control Programme; NALC$\mathrm{NaOH}$ : N-Acetyl-L-cysteine and sodium hydroxide; AFB: Acid-fast bacilli; BHI: Brain heart infusion agar.

\section{Supplementary Information}

The online version contains supplementary material available at https://doi. org/10.1186/s12941-021-00463-6.

Additional file 1: Table S1. Band pattern of mutations in gyrA gene by GenoType MTBDRs/ v.2.0 assay. Table S2. Band pattern of mutations in gyrB gene by GenoTypeMTBDRs/ v.2.0 assay. Table S3. Band pattern of mutations in rrs gene by GenoTypeMTBDRs/ v.2.0 assay. Table S4. Band pattern of mutations in eis gene by GenoTypeMTBDRs/ v.2.0 assay.

\section{Acknowledgements}

Authors acknowledge Uttar Pradesh National Health Mission (UPNHM), India for logistic support.

\section{Authors' contributions}

KS and SA designed the study. KS, RT, AS and VS collected the data. KS and SA analyzed data. KS, RK, SG, AG and SA interpreted the results. KS primarily wrote the manuscript. KS, RK, RT, SG, AG and SA provided valuable insight for revising the manuscript. All authors read and approved the final manuscript.

\section{Funding}

The current study is not supported by any funding agency.

\section{Availability of data and materials}

The datasets generated and/or analyzed during the current study are not publicly available due confidentiality agreement at the department of microbiology, Institute of Medical Sciences, Banaras Hindu University but are available from the corresponding author on reasonable request.

\section{Declarations}

\section{Ethics approval and consent to participate}

This study has been ethically approved by the Institute ethical committee of Institute of Medical Sciences (Ethical committee No-ECR/Bhu/Inst/UP/2013/ Re-registration-2017 dt. 31.01.2017 and Approval No- Dean/2018/EC/322), Banaras Hindu University, Varanasi.

\section{Consent for publication}

Not applicable.

\section{Competing interests}

The author(s) declare that they have no competing interests.

\section{Author details}

${ }^{1}$ Department of Microbiology, Institute of Medical Sciences, Banaras Hindu University, Varanasi, Uttar Pradesh, India. ${ }^{2}$ Department of Botany (Applied Microbiology), Institute of Science, Banaras Hindu University, Varanasi, Uttar Pradesh, India. ${ }^{3}$ Department of Biochemistry, Institute of Science, Banaras Hindu University, Varanasi, Uttar Pradesh, India.

Received: 22 February 2021 Accepted: 16 August 2021

Published online: 26 August 2021

References

1. Koch A, Cox H, Mizrahi V. Drug-resistant tuberculosis: challenges and opportunities for diagnosis and treatment. Curr Opin Pharmacol. 2018;42:7-15

2. Falzon D, Schünemann HJ, Harausz E, González-Angulo L, Lienhardt C, Jaramillo E, Weyer K. World Health Organization treatment guidelines for drug-resistant tuberculosis, 2016 update. Eur Respir J. 2017;49(3):1602308. 
3. Chen Y, Yuan Z, Shen X, Wu J, Wu Z, Xu B. Resistance to second-line antituberculosis drugs and delay in drug susceptibility testing among multidrug-resistant tuberculosis patients in Shanghai. BioMed Res Int. 2016. https://doi.org/10.1155/2016/2628913.

4. Prasad R, Singh A, Balasubramanian V, Gupta N. Extensively drug-resistant tuberculosis in India: current evidence on diagnosis \& management. Indian J Med Res. 2017;145(3):271.

5. Helb D, Jones M, Story E, Boehme C, Wallace E, Ho K, Kop J, Owens MR, Rodgers R, Banada P. Rapid detection of Mycobacterium tuberculosis and rifampin resistance by use of on-demand, near-patient technology. J Clin Microbiol. 2010;48(1):229-37.

6. Singh K, Kumari R, Tripathi R, Gupta A, Anupurba S. Mutation in MPT64 gene influencing diagnostic accuracy of SD Bioline assay (capilia). BMC Infect Dis. 2019;19(1):1-6.

7. Harding E. WHO global progress report on tuberculosis elimination. Lancet Respir Med. 2020;8(1):19.

8. Zeka AN, Tasbakan S, Cavusoglu C. Evaluation of the GeneXpert MTB/ RIF assay for rapid diagnosis of tuberculosis and detection of rifampin resistance in pulmonary and extrapulmonary specimens. J Clin Microbiol. 2011:49(12):4138-41.

9. Society AT. Diagnostic standards and classification of tuberculosis in adults and children. Am J Respir Crit Care Med. 2000;161:1376-95.

10. Rienthong S, Boonin C, Chaiyasirinrote B, Satproedprai N, Mahasirimongkol S, Yoshida H, Kondo Y, Namwat C, Rienthong D. Evaluation of a novel line-probe assay for genotyping-based diagnosis of Mycobacterium tuberculosis in Thailand. Int J Tuberc Lung Dis. 2015;19(7):817-22.

11. Chandak R, Malhotra B, Bhargava S, Goel S, Verma D, Tiwari J. Evaluation of MTBDRsl for detecting resistance in Mycobacterium tuberculosis to second-line drugs. Int J Tuberc Lung Dis. 2019;23(12):1257-62.

12. Gardee Y, Dreyer A, Koornhof H, Omar S, Da Silva P, Bhyat Z, Ismail NA. Evaluation of the GenoType MTBDRsI version 2.0 assay for second-line drug resistance detection of Mycobacterium tuberculosis isolates in South Africa. J Clin Microbiol. 2017:55(3):791-800.

13. Rufai SB, Umay K, Singh PK, Singh S. Performance of Genotype MTBDR sl V2. 0 over the Genotype MTBDR sI V1 for detection of second line drug resistance: an Indian perspective. PLoS ONE. 2020;15(3):e0229419.

14. Siddiqi S, Rüsch-Gerdes S. MGIT procedure manual. Foundation for Innovative New Diagnostics. Geneva: Switzerland; 2006. p. 41-51.

15. Bemer P, Palicova F, Rüsch-Gerdes S, Drugeon HB, Pfyffer GE. Multicenter evaluation of fully automated BACTEC Mycobacteria Growth Indicator Tube 960 system for susceptibility testing of Mycobacterium tuberculosis. J Clin Microbiol. 2002:40(1):150-4.

16. Shenoy VP, Mukhopadhyay C. Rapid immunochromatographic test for the identification and discrimination of Mycobacterium tuberculosis complex isolates from non-tuberculous mycobacteria. J Clin Diagn Res. 2014;8(4):DC13.

17. Ignatyeva O, Kontsevaya I, Kovalyov A, Balabanova Y, Nikolayevskyy V, Toit K, Dragan A, Maxim D, Mironova S, Kummik T. Detection of resistance to second-line antituberculosis drugs by use of the genotype MTBDRsl assay: a multicenter evaluation and feasibility study. J Clin Microbiol. 2012;50(5):1593-7.

18. Sethi S, Agarwal P, Khaneja R, Kumar N, Kumar N, Chandna J, Aggarwal AN, Yadav R. Second-line drug resistance characterization in Mycobacterium tuberculosis by genotype MTBDRsl assay. J Epidemiol Global Health. 2020;10(1):42

19. Kambli P, Ajbani K, Sadani M, Nikam C, Shetty A, Udwadia Z, Rodwell TC, Catanzaro A, Rodrigues C. Correlating minimum inhibitory concentrations of ofloxacin and moxifloxacin with gyrA mutations using the genotype MTBDRsl assay. Tuberculosis. 2015;95(2):137-41.

20. Javed H, Bakuła Z, Pleń M, Hashmi HJ, Tahir Z, Jamil N, Jagielski T. Evaluation of genotype MTBDRplus and MTBDRsl assays for rapid detection of drug resistance in extensively drug-resistant Mycobacterium tuberculosis isolates in Pakistan. Front Microbiol. 2018;9:2265.

21. Tagliani E, Cabibbe AM, Miotto P, Borroni E, Toro JC, Mansjö M, Hoffner S, Hillemann D, Zalutskaya A, Skrahina A. Diagnostic performance of the new version (v2. 0) of GenoType MTBDRsl assay for detection of resistance to fluoroquinolones and second-line injectable drugs: a multicenter study. J Clin Microbiol. 2015;53(9):2961-9.

22. Bang D, Andersen SR, Vasiliauskienè E, Rasmussen EM. Performance of the GenoType MTBDRplus assay (v2. 0) and a new extended GenoType MTBDRsl assay (v2. 0) for the molecular detection of multi-and extensively drug-resistant Mycobacterium tuberculosis on isolates primarily from Lithuania. Diagn Microbiol Infect Dis. 2016;86(4):377-81.

23. Brossier F, Guindo D, Pham A, Reibel F, Sougakoff W, Veziris N, Aubry A. Performance of the new version (v2. 0) of the GenoType MTBDRsl test for detection of resistance to second-line drugs in multidrugresistant Mycobacterium tuberculosis complex strains. J Clin Microbiol. 2016;54(6):1573-80.

24. Yadav R, Saini A, Kaur P, Behera D, Sethi S. Diagnostic accuracy of GenoType ${ }^{\circledR}$ MTBDRsI VER 2.0 in detecting second-line drug resistance to $M$. tuberculosis. Int J Tuberculosis Lung Dis. 2018;22(4):419-24.

25. Li G, Guo Q, Liu H, Wan L, Jiang Y, Li M, Zhao L-L, Zhao X, Liu Z, Wan K. Detection of resistance to fluoroquinolones and second-line injectable drugs among Mycobacterium tuberculosis by a reverse dot blot hybridization assay. Infect Drug Resist. 2020;13:4091.

26. Ramakrishna V, Singh PK, Prakash S, Jain A. Second line injectable drug resistance and associated genetic mutations in newly diagnosed cases of multidrug-resistant tuberculosis. Microb Drug Resist. 2020;26(8):971-5.

27. Singh N, Singh PK, Singh U, Garg R, Jain A. Fluroquinolone drug resistance among MDR-TB patients increases the risk of unfavourable interim microbiological treatment outcome: an observational study. J Glob Antimicrob Resiste. 2021;24:40-4.

\section{Publisher's Note}

Springer Nature remains neutral with regard to jurisdictional claims in published maps and institutional affiliations.
Ready to submit your research? Choose BMC and benefit from:

- fast, convenient online submission

- thorough peer review by experienced researchers in your field

- rapid publication on acceptance

- support for research data, including large and complex data types

- gold Open Access which fosters wider collaboration and increased citations

- maximum visibility for your research: over 100M website views per year

At BMC, research is always in progress.

Learn more biomedcentral.com/submissions 